\title{
Casandra trágica
}

\author{
Ana Iriarte \\ Universidad del País Vasco
}

\section{Resumen}

Este articulo centra su discurso en la figura de Casandra, pero no para insistir de nuevo sobre esta princesa troyana en cuanto que símbolo de la falta de reconocimiento público del discurso fennenino. Se analiza cóno aparece insctita Casandra en el contexto de la tragedia gricga. Casandra constituye uno de los paradigmas trágicos mejor cualificados para explicar el marizado razonamienco que tragedia despliega al poner en escena la siempre polé. mica relación entre el principio femenino y el principio masculino. Por ello la figura de Casandra cs analizada en cuanto que prototipo de doncella, csposa legitima y cxtranjera en rerricorio griego $\mathrm{y}$, por último, como potencia vengadora.

Palabras clave: Casandra, tragedia, femenino.

\section{Abstract. Cassandra tragical}

This article focuses on the figure of Cassandra, not in order to reiterate the Trojan princess's value as a symbol of the lack of public recognition of feminine discourse, but rather to analyse Cassandra's position within the context of Greek tragedy. Cassandra is one of the tragic patadignis which best illustrate the subtle reasoning with which tragedy stages the ever controversial relationship between the feminine and the masculine principles. The figure of Cassandra is therefore analysed as the prototype of virgin, lawful wife and foreigner in Greek territory and, ultinately, as an avenging power.

Key words: Cassandra, tragedy, feminine.

\section{Sumario}
1. Casandra parthénos
3. Casandra Erinia
2. Casandra esposa legítima y extranjera
4. La muerte de Casandra

Erase una vez Casandra, la princesa troyana que obtuvo de Apolo el don profético a cambio de la promesa de entregarse a él, pero que finalmente rechazó el amor del dios, por lo que éste la condenó a que nadie creyera jamás sus oráculos. 
Desde el arcaismo griego esta célebre figura mitológica aparece con tanto recato como perseverancia en la tradición literaria occidental, llegando a convertirse en símbolo de la falta dc reconocimiento público del discurso femenino. No obstante, las páginas que siguen se limitarán a considerarla tal y como aparecc inscrita en el contexto de la tragedia griega, lo cual requiere algún comentario inicial sobre este género triunfante en la Atenas del s. v. aC.

Las obras de los poetas trágicos no se representaban para complacer a los aficionados al teatro, sino que iban dirigidas a todo el cuerpo cívico atenicnse. Un público, eso sí, del que no parece que formaran parte las mujeres. En estas representaciones, los relatos míticos referidos a una sociedad heroica ya desaparecida se reutilizan para interpretar el presente de la ciudad y cuestionar los discursos oficiales que en ella imperan. De tal manera que pucde decirse que la base fundamental de la tragedia es el pensamiento social característico de la polis ${ }^{1}$. $\mathrm{O}$, si se prefiere, el pensamiento político entendido globalmente.

Contrariamente a esa función marginal, o simplemente recreativa, a la que el tcatro ha sido relegado en sociedades como la nuestra, la tragedia griega se sitúa en cl centro de la reflexión de los ciudadanos atenienses sobre su propia identidad. Ahora bien, si tenemos en cuenta que, en Atenas, el ciudadano se define mediante la doble afirmación "de su estatus de varón, y de su filiación ateniensen ${ }^{2}$, resulta fácil entender que la polaridad masculino/femenino ocupe un lugar destacado en esta forma de discurso cívico que es la tragedia.

La importancia de los papeles que estas obras reservan a la mujer fue observada desde la propia antigüedad, dando lugar a una serie de comentarios sobre la ventaja o el inconveniente que el protagonismo de las heroínas trágicas podía suponer para la considcración del género femenino.

Así, en la obra del cómico Aristófanes, Eurípides es acusado en los siguientes términos por una de las participantes en las Tesmoforias, fiesta que reunía exclusivamente a las esposas de los atenienses: «Estoy indignada desde hace tiempo al ver cómo somos injuriadas por Eurípides cl hijo de la verdulera y que recibimos de él toda clase de acusaciones. ¿Pues con quć desgracia deja éste de ensuciarnos? ¿Y en qué lugar no nos ha calumniado, con tal que haya espectadores, tragedias y coros, llamándonos adúlteras, locas por los hombres, borrachas, pura corrupción, gran desgracia para los varones? ${ }^{3}$.

Varios siglos después Ateneo (s. II o III dC) retomará esta polémica relatando, con evidente ironía, que cuando alguien comentó ante Sófocles que Eurípides «era misógino", el primero contestó que Eurípides amaba a las mujeres "al menos en la cama".

Puede decirse que, desde la denuncia de Aristófanes, el debate sobre la posi-

1. Vernant, J.P. y Vidal-Naquet P. Mito y tragedia. Madrid: Taurus, 1987 y 1989, 2 t.; Mcicr, Ch. La tragédie greeque comme art politigue. Paris: Les Belles Lettres, 1991.

2. Loraux, N. Les enfants d'Athéna. Paris: F. Maspero, 1981, p. 20.

3. Aristúfanes. Tesmoforids, 384-391 (trad. F. Rodríguez Adrados).

4. Ateneo, XIII,557e. Cf. ibídcm, XIII, 603e. 
ble misoginia de Eurípides ${ }^{5}$ y del género trágico en general se ha prolongado hasta nuestros días manteniendo un enfoque muy similar: a la consideración de la tragedia como "negativa" para la imagen femenina, viene a oponerse la corriente que atribuye a dicho género una visión feminista avant la lettre ${ }^{6}$.

El protagonismo femenino en el teatro trágico ha sido también muy estudiado desde el punto de vista de su contraste con una realidad histórica que exigía la máxima discreción a la mujer. En este sentido Helene Foley ${ }^{7}$ ha avanzado la hipótesis de que se trata de una compensación necesaria al eclipse que la mujer griega sufre en su vida cotidiana. Para ello la autora establece una distinción, demasiado estricta quizás, entre el drama ático como reflejo de lo imaginario y los textos en prosa como portadores de una información real sobre el estatus jurídico y social de la mujer en Atenas.

Retomando obras en prosa del s. IV, en especial los discursos de los oradores, Helene Foley llega a la conclusión de que en dichas fuentes «la función reproductora de la mujer justifica su exclusión de la vida pública". En cuanto a su propuesta para el análisis del propio drama ático entronca con una corriente interpretativa muy fructífera que critica la aplicación rigurosa de la ecuación según la cual la mujer se situaría sistemáticamente del lado de la naturaleza y del espacio interior, mientras que el hombre lo haría del lado de la cultura y del dominio público.

Esta ecuación, tan utilizada por los estructuralistas, tiene una indiscutible razón de ser. El antagonismo entre mujer/espacio interior, hombre/dominio público es central en la tragedia a partir del momento en que ésta acostumbra a representar el universo doméstico del antiguo - y en gran parte imaginario- sistema palacial para reflexionar sobre el sistema radicalmente diferente de la ciudad-estado. Ahora bien, el marcado carácter político de los enredos que afectan a las familias reales señala por sí solo la interacción inevitable que se va a producir entre dominio público y privado, entre funciones femeninas y masculinas. Una interacción que no puede ser desatendida en nombre de reivindicaciones excluyentes de cualquiera de estos polos opuestos.

Lo que quisiera mostrar al hilo de estas consideraciones es que la figura de Casandra constituye uno de los paradigmas trágicos mejor cualificados para

5. Sobre la ambiguiedad de la postura de Eurípides con respecto al género femenino, ver Nancy. "Euripide et le parti des femmes". En La femme dans les sociétés antiques. Strasbourg, 1983, p. 73-92. Eva Cantarella (La Calamidad ambigua. Trad. esp. Madrid: Ediciones Clásicas, 1991) evoca el debate al que nos referimos posicionándose sin rodeos al concluir que es fácil detectar en la tragedia da antigua misoginia y la igualmente antigua idea de la necesaria subordinación femenina” (p. 112).

6. Por ejemplo, para Sarah B. Pomeroy (Diosas, rameras, esposas y esclavas. Madrid: Akal, 1987, p. 127) la postura de Eurípides resulta muy favorable: "Yo no le creo misógino por el hecho de que presente a mujeres fuertes, discutidoras, triunfantes y sexualmente exigentes, aunque también sean egoistas o perversas. Orras feministas comparten mi opinión, y las sufragistas británicas solían recitar fragmentos de Eurípides en sus mítines".

7. "The Conception of Women in Athenian Drama". En FOLEY, Helene P. (ed.). Reflections of Women in Antiquity. Nueva York-Londres-París, 1981, p. 132. 
dar cuenta del matizado razonamiento que los poetas trágicos dcsplicgan cuando se trata de presentar en escena la siempre polémica relación entre el principio femenino y el masculino. Para ello consideraré fundamentalmente a Casandra como prototipo de doncella, como esposa legítima y extranjera en territorio griego y, finalmente, como potencia vengadora. Pero ante todo debo señalar que me escudo en el hecho de haber publicado algunas páginas sobre esta figu$\mathrm{ra}^{8}$ para dejar de lado en esta ocasión la importante faceta sobrenatural que le otorga su relación con Apolo, así como el particular discurso por el que se le reconoce como una "mujer sabia".

Resulta difícil imaginar a Casandra desprovista de su función profética. Sin embargo, así es como aparece por primera vez en la literatura: en la Ilíada Casandra es simplemente la más bella de las hijas de Príamo, la única a la que se le conoce por su nombre. Este monarca la había prometido a Otrioneo" a cambio de una gran hazaña en la guerra contra los griegos. Pero Otrioneo muere en el campo de batalla y, desaparecido el pretendientc, cl intercambio en el que Casandra había sido propuesta como recompensa no se llevará a cabo. Así es como se inaugura su carrera de "doncella".

En la visita que, de camino a Itaca, Ulises hace a los infiernos, Agamenón le cuenta que en el momento de ser asesinado, escuchó «la misćrrima voz de Casandra, hija de Príamon, a la cual estaban matando junto a él. Estos versos de la Odisea permiten adivinar cómo la princesa fue otorgada a Agamenón tras la caída de Troya y asesinada junto a este rey al llegar a Grecia ${ }^{10}$.

Píndaro es el primer autor conocido que alude al don profético de Casandra reconociéndola como la "virgen profeta" $"$. Y el poeta Alceo la presenta como víctima de los cxccsos de Ayante durante el saqueo de Troya ${ }^{12}$, concretamente en el templo de Atenea, diosa protectora de la virginidad, cn donde Casandra sc había refugiado ${ }^{13}$.

Tales son los rasgos básicos de la biografía quc la literatura arcaica conservada hasta nuestros días atribuye a Casandra. Entre ellos la conflictiva relación con el jefe de la armada griega, junto con la que la une a Apolo, serán privile-

8. A. Iriarte. Las redes del enigma. Vaces femeninas en el pensamiento griego. Madrid: Taurus, 1990, p. 104 ss.

9. Homero, lliada, XIII, 363 ss.

10. Ídem, Odisea, XI, 421

1I. Píndato. Piticas, XI, 32.

12. Seguramente la escena fue tratada en detalle por el poeta de la epopeya Iliupersis. Esquilo no alude a ella, pero el episodio scrá cvocado por Euripides en el prólogo de las Troyanas -en donde Atenea se lamenta junto con Poseidón de que los griegos no han castigado a Ayante por su comportamiento - y en el v. 617 - en donde Agamenón es considerado como un segundo Ayante. Licofrón (Alejandra, 348-364) designará explícitamente el acto de Ayante como una violación.

13. Fr. 138 en PAGe D.L. Lyrica Graeca Selecta. Oxford, 1968, p. 75. Fragmento reeditado por LLOYD-JONFs. "The Cologne Fragment of Alcaeus". GRBS, IX (1968), p. 125-39. TARDIT, G. "L'asebeia di Aiace e quella di Pittaco". QUCC, VIII(1969), p. 86-96. Para la importancia de este episodio en la tradición artística, véase DAVREUX J. La légende de la prophétesse Cassandre. Licja, 1949, p.138-211. 
giados en las dos obras trágicas que más atención le dedican: el Agamenón de Esquilo y las Troyanas de Eurípides. Dos obras muy relacionadas entre sí, pues, a mi modo de ver y en lo que a Casandra se refiere las Troyanas -representadas en el $415 \mathrm{aC}$ - tienen mucho de lectura-respuesta a la obra que Esquilo había representado unos 40 años antes -en el $458 \mathrm{aC}^{14}$.

Como personaje trágico prototipo, Casandra se sitúa en ambas ocasiones en un momento de transición, un recurso que es del todo propio del género: la escena de Casandra en el Agamenón transcurre cuando acaba de llegar a la ciudad griega de Argos, entre el momento en que su carruaje se detiene ante el palacio real y el momento en que penetra en dicho palacio para morir, mientras que los versos que se le dedican en las Troyanas refieren el estado de Casandra en otro momento de transición: aquel en el que sigue en Troya junto a su madre aunque ya ha sido destinada a Agamenón.

Pero, además de ser representada en el umbral que separa el mundo de los vivos del de los muertos y en la frontera entre Oriente y Occidente, Casandra se sitúa permanentemente en un espacio indeterminado entre el humano que le es propio y el divino al que le da acceso la inspiración profética. Su existencia se desarrolla alternativamente en los dos niveles dado que ella misma racionaliza los oráculos que ha pronunciado en estado de posesión divina.

Estas siruaciones equívocas se revelan especialmente adecuadas para exponer los diferentes estatus sociales que, según la atípica lógica del discurso trágico, van a manifestarse en el personaje simultáneamente: el de doncella, el de esposa legítima y el de excranjera.

\section{Casandra parthénos}

Repetidamente amenazada por la violación, el deseo de Apolo y la unión forzosa con Agamenón, Casandra refuerza en cada una de estas situaciones su condición de udoncella». Dicho de orra forma, el rapto de Ayante, la presión apolínca y cl tipo de vasallaje que le impone Agamenón, son tres tipos de comportamiento masculino que dan cuenta del marcado carácter "virginal" de nuestra figura, pues uen la perspectiva griega la adolescencia se caracteriza precisamente por el hecho de que durante este periodo la joven, que ya es púber pero todavía no está casada, suscita el deseo de los hombres rechazando al mismo tiempo sus proposiciones. Por consiguiente induce a los seducidos al acto violento" 15 .

Con respecto a Apolo, la virginidad de Casandra se explica desde dos coordenadas que no tienen por qué converger.

La conversación que Casandra mantiene con el coro del Agamenón deja constancia de que su elección fue perpetuar su condición virginal a pesar del

14. Por mucho que Rachel Aélion (Euripide héritier d'Eschyle. París, 1983) no preste especial interés por nuestro personaje.

15. Como señala CALAME, Claude. Les choeurs de jeunes filles en Grèce archä̈que. Roma, 1977, t. I, p. 256. 
deseo del dios y de que su rechazo provocó la cólera y el castigo del mismo ${ }^{26}$. Esta experiencia asocia el caso de Casandra al tcma mítico de las doncellas forzadas por Apolo entre las que se encuentra la princesa ateniense Creusa, que se vio forzada a unirse a él ${ }^{17}$; Dafne, la ninfa que tuvo que transformarse en laurel para evitar al dios ${ }^{18}$; o la cazadora Cirene ${ }^{19}$, que fue raptada por el mismo, al igual que Marpesa ${ }^{20}$.

Ial y como ocurre con Casandra, la venganza de Apolo se cierne sobre todas aquellas que, dc una forma u otra, lo rechazan, lo engañan o se le resisten. Así, Creusa permanecerá estéril tras haber dado a luz un hijo del dios. La joven Corónide ${ }^{21}$ morirá abrasada por haberle sido infiel y la Sibila de Cumas ${ }^{2 ?}$, que se había negado a "entregarle su virginidad", será condenada a una vcjez interminable durante la cual disminuye de tamaño hasta alcanzar las dimensiones de una cigarra ${ }^{23}$.

No obstante, la lectura que Eurípides hace de la obra de Esquilo corrige esta versión de los hechos que tiende a incluir a Casandra en la larga lista de jóvenes víctimas de Apolo. En las Troyanas la virginidad de la profetisa se explica en tanto que tecompensa del dios al que está consagrada ${ }^{24}$, por lo que la decisión del rey griego que la ha elegido como compañcra será tachada de impia en los siguientes términos: "A Casandra, a la cual convirtió $A$ polo en delirante virgen, Agamenón quicre, con desprecio del dios y la piedad, tomarla por fuerza como esposa secretan ${ }^{25}$. Así es como Eurípides se refiere cxplícitamente a la concepción, habitual entre los griegos, de que las profetisas no deben unirse a ningún mortal para preservar la estrecha rclación que las une a la divinidad.

La ambigüedad de esta figura dividida entre su condición de profetisa, de hija y de cautiva, queda reflejada en esta obra mediante tres términos: Casandra será parthénos ${ }^{26}$, kóre ${ }^{27}$ o ny'mphe ${ }^{28}$, según se trate de su relación con Apolo, con su madre o con Agamenón. Tres términos que se fijan en una noción inter-

16. Esquilo, Agamenón, 1203-14. Aunque en estit obra Casandra no es designada explícitamente como "virgen".

17. EuRÍptDFs. Ion, 10-11.

18. Оүптіо. Metamorfosis, $1,452 \mathrm{ss}$.

19. Pindaro. Piticas, IX, 20-75.

20. HOMERO. Iliada, IX, 557-564.

21. PIndaro, Píticas, III, 25-45.

22. VIRGILIO. Eneida, VI, $10 \mathrm{ss}$.

23. C. Miralles, en su artículo "Le spose di Zeus e l'otdine del mondo nella Tegonia di Esiodo". En BEITIN!, M. (ed.). Maschile/Femminile. Genere e rwoli nelle culture antiche Roma-Bari: Laterza, 1992, señala cómo estos encuentrtros violentos o frustrados con ninfas resituan pertranentemente a Apolo cn su estatus de koḱros. Ma T. Clavo, por su parte, propone una explicación del tema mítico de los amores de Apolo en base a la función iniciática de este dios: «Ninfas de Apolo, ninfas de Dioniso", Faventia, 8/2 (1986), p. 5-20.

24. $253-254$ y $45 \mathrm{I}-454$.

25. $41-44$.

26. 44.253 y 324 .

27. 341. Cf. FurIPIDES, Electra, 1032.

28. 337 y 420 . Cf. Eurípides, Electra, 1033 . 
media entre "muchacha» y "recién casada»" 29 , dando cuenta, en todo caso, de la condición de una joven que en modo alguno se ha convertido en esposa realizada, es decir, en madre.

Como ya hemos recordado, en las Troyanas Casandra todavía no se ha alejado definitivamente del espacio familiar y este hecho autoriza una particular insistencia en su "castidad", hágneuma ${ }^{30}$. La pureza reconocida en Casandra llega incluso a reforzarse en relación con el matrimonio que la unirá al rey griego a partir del momento en que dicha unión sólo se concibe en el contexto del Hades ${ }^{31}$. En efecto, esta asociación entre matrimonio y muerte debe enrenderse como manera de acentuar la idea de su condición virginal, pucs en Grecia existe una concepción muy arraigada según la cual el matrimonio de una doncella es concebido como muerte y viceversa 33 .

Una vez más, la fiel lectura que Eurípides hace de la obra de Esquilo sc deja adivinar bajo forma de inversión, pues en las Troyanas la unión de la profetisa con un mortal se piensa en forma de tnuerte, mientras que en el Agamenón la muerte conjunta se convierre en símbolo de la unión entre cstas dos figuras. $\Lambda$ sí lo dan a entender las palabras con las que Clitemestra, la madre de los hijos de Agamenón, acompaña su doble asesinato: "Ahí yace el ofensor de esta esposa [...], y también la prisionera, la adivina, su vidente y compańera de lecho, compartiendo ahora fielmente su cama como había compartido su banco en el mar"33. Asimismo, Casandra identificará las puertas del palacio con las puertas del $\mathrm{Hades}^{34}$, puesto que arravesar las primeras implica unirse con $\mathrm{cl}$ rey cn una muerte conjunta.

Pasemos, pues, a ocuparnos del tratamiento jurídico que merece esta unión.

\section{Casandra esposa legítima y extranjera}

En la obra de Fsquilo Casandra es una esclava que forma parte del botín de gucrra de Agamenón y la importancia que reviste para éste se manifiesta en la

29. Sin designar concretamente ninguno de ellos, como señala GERNET, L. "Frairies antiques". Anthropologie de la Grèce Antique. París: F. Maspscro, 1976, p. 41. P. Chantraine (Dictionnaire étimologique de la langue grecque. Histoire dés mots. Paris, 1968, s.v.) señaló, no obstante, que el cérmino parthénos es el que más claramente traduce la idea de virginidad. Sobre cste. tema consultar el significativo trabajo de SISSA, G. Le corps virginal. Ia virginité féminine en Grèce ancienne. París; Vrin, 1987.

30. 453 y 501 .

31. 445 .

32. Ver, por ejemplo, Eurílínes, Hécuba, 368 y Antología Palatina, VII, 182. El paradigma mítico que con mayor transparencia refleja esta concepción del pensamiento griego es el de lerséfone, quien, tras haberse casado con Hades, dios de los infiernos, sigue respondiendo a la denominación de Core, de "hijan de Deméter. Véase, KaHN,L. y Loraux, N. "Perséphone: la jeune fille et la mort". En Bonnefor, Y, (ed.). Dictionnaire des mytholo. gies. París, 1981 , t. II, p. 117 ss.: «Mort comme mariage, mariage comme mort: ce sont là des métaphores équivalentes et coujour's pérnutables".

33. Esquilo, Agamenón, 1438-43.

34. Ibidem, 1291. 
solicitud con la que la confía a su esposa: " $\Lambda$ coge en palacio benévolamente a esta extranjera, que con agrado mira la deidad desde lejos al que ejerce el poder con benignidad, porque nadie lleva por su gusto el yugo de la esclavitud. Ella, como flor escogida de entre muchas riquezas, un regalo (dórema) que me ha hecho el cjército, ha verido conmigon ${ }^{35}$.

Esclava se considerará a sí misma Casandra ${ }^{36}$, y como tal será acngida tanto por Clitemestra ${ }^{37}$ como por el coro de ancianos que la recibe ${ }^{38}$. Pero lo cierto es que en los versos que acabo de citar se hace un empleo muy astuto del cautiverio de Casandra para suavizar ante la esposa legítima la noticia de la relación más íntima que la une al rey, ya que un poco más adelante se la identificará como "esposa legítima" (gyne $)^{39}$ del mismo.

Dicha legitimidad ${ }^{40}$ se da a entender sobre todo mediantc la identificación constante entre la princesa troyana y Clitemestra ${ }^{41}$. Así, cuando Casandra profetiza que la reina será asesinada, dice textualmente: «como compensación por mi muerte, la muerte de una mujer, otra mujer morirán, utilizando tanto para Clitemestra como para sí misma el término gynét2, que es el más usual para designar a la mujer casada ${ }^{43}$.

Esta tendencia a la legalización de los lazos que uner a Casandra con su amo será acentuada por Eurípides. Como decía, estc poeta sólo puede evocar la unión de Casandra y Agamenón como un proyecto de futuro, ya que en las Troyanas la princesa todavía no ha salido de su entorno familiar. Pero ello no impide que, cuando se croca la futura unión de la princesa con el rey, se hable de "matrimonio" 4 .

35. Ibíden, 950-955.

36. Ibídem, 1326.

37. Ibidem, 1035 .

38. Ibídem, 1084.

39. Ibídem, 954 y 1296 .

40. Pausanias (II, 16, 6) es el único autor que atribuye dos hijos a Casandra y Agamenón: Teledamo y Pélope, quienes habrían sido ascsinados por Egisro.

41. Para la misma identificación de estas dos figuras mediante cl término nymphe, ver Eurípides, Troyanas, 337 y 420 (a propósito de Casandra), 250 (a propósito de Clitemestra); para la senejanza del lenguaje que se les atribuye, ver, IRLARTE, A. Redes. p. 122 ss.

42. 1318.

43. Además, las dos mujeres designan su relación con el rey mediante el mismo calificativo, syneunos: la profetisa anunciará que la asesina de Agamenón es au "compañera de cama" (1116), mientras que Clitemestra, una vez realizado el doble asesinato, comunica al coro que el rey ha caído junto con su "compañera de cama" (1442). Syneunoses un término ambiguo para definir la legalidad de estas uniones ya que remite a euné, la "cama" como el lecho amoroso más que como institución (léchos). Pero, como señala P. Chantraine (s.v. euné), es frecuente quc en poesía este término designe el lecho nupcial y el matrimonio. De hecho, según el discurso de Apolo en las Esquilo, Euménides (217-18), el "lecho amoroso" (eune) es la mayor prueba de la legitimidad matrimonial: "el lecho conyugal que asigna el destino al esposo y la esposa tiene más fuerza que un juramento, porque está custodiado por la justiciar.

44. Mediante la utilización del verbo gaméo, que expresa el lazo social que une a marido y mujer. Este verbo, con sus formas nominales, se emplea con insistencia a propósito de la unión entre $\Lambda$ gamenón y Casandra: Euripides, Troyanas, 44, 311, 313, 319, 339, 343, 347, $352,357,363,405,445$. 
Si en Esquilo el estado jurídico de Casandra se sitúa entre el de esclava y el de esposa legítima, la lectura de Eurípides subraya esta ambiguiedad intentando zanjarla al mismo tiempo. Así, cuando la madre de Casandra pregunta al mensajero si su hija ha sido otorgada a Agamenón para ser esclava, éste le responde: «no, un matrimonio secreto (léktron skótia) la unirá a su novio ${ }^{45}$.

En Eurípides los diferentes estatus de Casandra con respecto a los mortales se presentan como problemáticos desde el punto de vista de la relación fundamental que esta doncella mantiene con el dios. Sin embargo, la cuestión que Esquilo prefierc intcrrogar en cscena es la indeterminación del estado de Casandra, esposa legítima y cautiva, con respecto al palacio de los Atridas y, en última instancia, a la ciudad griega.

De la cxistencia de tal prcocupación da cuenta, además, una rercera facera que vamos a considerar: la de "extranjera».

En principio, la denominación de xéne $e^{46}$ señala tan sólo el estatus de la asiática Casandra con respecto al territorio griego ${ }^{47}$, aunque, como veremos, dicha denominación vuelve a reunir varias facetas de nuestra protagonista.

Cuando Agamenón pide a Clitemestra que "acoja" 48 a Casandra está evocando una institución cuya existencia se remonta al alba de la cultura griega: la de la hospitalidad o xenia. En sentido estricto la hospitalidad cra cl pacto de acogida establecido entre dos familias extranjeras, principalmente aristócratas. Dicho pacto obligaba al anfitrión a comportarse con arreglo a un estricto código moral y podía desembocar en intercambios matrimonialcs. Pcro la xenía puede consistir también en una práctica hospitalaria más simple que se cstablecía entre individuos, no entre grupos familiares, y de la que podía beneficiarse cualquier viajero, rico o pobre, que llegara al país ${ }^{19}$.

Visiblemente la acogida que Agamenón reclama para Casandra tiene más que ver con esta segunda forma de hospicalidad. La insistencia por parte del rey en que la princesa troyana merece más atención que cualquier otro de los recién llegados indica que lo que define la parcicular situación de Casandra no cs tanto su condición de extranjera y de esclava como la deferencia de la que parece merecedora ${ }^{50}$.

45. Euripides, Troyanas, 253. Fste posta cs todavia más explicito en la Electra (1033-1031) cuando atribuye a Clitemestra la siguiente queja: "eramos dos esposas viviendo bajo el mismo techo".

46. En el Agamenón Casandra es denominada así en dos ocasiones: por el rey en el verso 950 y por el coro en el verso 1062.

47. Sólo Clitemestra aludirá indircctamente a su condición de hárhara mediante el término kárbanos: ESQullo. Agamenón, 1061.

48. F.l verbo empleado es komiza, que puede utilizarse en el sentido de "dat la hospitalidad a alguien: I IOMERo. Iliada, VIII, 284.

19. Sobre estas dos modalidades de xenia, ver GAUTHIER, Ph. Symbola. Les étrangers et la justice dans les cités grecques. Nancy: Université de Nancy, 1977, p.18 ss., y p. 24-25 para orros ejemplos rrágicos de acogida y protección de mujeres extranjeras por parte del rey.

50. P. Roth ("The thetne of Corrupted Xenia in Aesclyylus' Orestian. Mnemosyne, XLVI, 1(1993), p. 5-7) ha señalado cómo Clitemestra asume el papel de anfitrión cuando recibe a su mari- 
Por otra parte, el carácter legítimo que pot momentos reviste su relación con el rey induce a tener en cuenta que, en la época de Esquilo, la esposa también participa del estatus de extranjera ya que al casarse la joven pasa a formar parte de un espacio familiar que le es extraño y en el que es considerada como extraña: el de su esposo.

Desde la perspectiva ateniensc ${ }^{51}$, estc desplazamiento responde a una finalidad bien precisa, pues la condición dc extranjera de la esposa ${ }^{52}$ permite la continuidad de una herencia puramente paternal. En las Euménides Esquilo expondrá esta concepción ateniense de forma tan clara como sigue: "No es la llamada madre la que engendra al hijo, sino que es sólo la nodriza dcl embrión recién sembrado. Engendra el que fecunda, mientras que ella, como una extranjeta para un extranjero (xéno xéne), sólo conserva el brote» ${ }^{53}$.

En resumen, el empleo del calificativo de "extranjera", lejos de determinar la condición social de Casandra sigue evocando la ambigijedad de dicha condición al resituar a nuestra protagonista en la intersección del estado de "invitada de honor", de "esclava oriental" y de «esposa». Una ambigüedad que rcmite, dicho sea de paso, a la identificación entre el espacio de la polis al que Casandra acaba de llegar y el espacio doméstico en el que está a punto de integrarse. Una ambigüedad que muestra, en definitiva, cómo en el contexto de la tragedia, la oposición espacio privado/espacio públiço no permanece inalterada, ya que estos dos dominios pueden presentarse como correlativos.

En la obra de Sófocles encontramos un caso muy similar de integración de una extranjera en el seno de un palacio gricgo. Se trata de la figura de Yole, la joven prisionera que Heracles ha desposado en secreto ${ }^{54}$ antes de enviarla a su palacio "como si fuera una esclava más" 55 .

do y a Casandra, pero sólo lo hace para invertir la costumbre de ofrecer un baño y ropa limpia al viajero, gues, como se sabe, la invicación de la reina es un pretexto para hacerles entrar y darles muertc.

51. Sobre la desventaja del estatus de la esposa como consecuencia del proceso de renuncia a la posesión de riquezas uincrustées dans le territoire" y del distanciamiento de las formas de "structure en maisons" que sufre la comunidad cívica ateniense, ver, LEDUC, Cl. "Comment la donner en mariage?m. En DUbY G. y PeRRoI, M. Histoire des Femmes. I. L'antiquité. París, 1991, p. 259 ss. (trad. esp., Madrid: Taurus, 1991).

52. Una concepción que se refleja claramente en el rito de integración que la recitén casada protagonira al llegar a casa de su csposo. Rito que es similar al que se lleva a cabo para adoptar un nuevo esclavo en la casa y que consistía en conducir a la recién llcgada junto al fogón y verter sobre su cabeza diversos tipos de frutos secos (nucces, dátiles, higos...): VERNANT, J.P. "Hestia-Hermès». Mythe et Pensé?. París: F. Maspero, 1974, t.I, p. 130-132. Sobre los diferentes grados dc exclusión de los que, en Acenas, son objeto las mujeres - que conforman la mitad de la ciudad-y los esclavos -que no forman pare de ella-, ver VIDAL-NAQUET, P. "Esclavage et gynécocratie dans la tradition, le mythe, l'utopie". En Le chasseur noir. París: F. Maspero, 1981, p. 267-88.

53. EsQuilo, Eumenides, 658-61.

54. SOFOCles. Traquinias 360.

55. Ibídem, 367. 
Al igual que Casandra, Yole, en el entrecruzamiento de su condición de "esclava" y de "extranjera" 56 , es considerada "esposa legítima" 57 . Cuando Deyanira, la esposa de Heracles, la recibe ante su palacio se queja en los siguientes términos: uel vivir con esta joven en el mismo lugar, ¿̨qué mujer podría hacerlo compartiendo la misma unión, gámon? "s8. Un comentario idéntico, por cierto, al que Eurípides atribuye a Clitemestra: «éramos dos esposas viviendo bajo el mismo techo: ${ }^{52}$. La intcgración de cstas dos princesas en los hogares de sus amos no se plantea, por lo tanto, como una unión servil, sino que nos sitúa frente a la problemática de una doble alianza legítima ${ }^{60}$.

T a poligamia era una práctica totalmente anacrónica en la $\Lambda$ tcnas democrática que conocieron los trágicos. Sin embargo, estos poetas gustan de representarla desde la perspectiva crítica propia de la sociedad monngámica en la que ellos se desenvuelven, por lo que la doble alianza legítima aparcce cn escena como una práctica aberrante; y aberrante, ante todo, desde el punto de vista jurídico, como lo indica el hecho de que la conflictividad que se le atribuye se exprese más en términos de imposibilidad jurídica que de discurso amoroso.

De esta mancra los trágicos se hacen eco de una preocupación fundamental en la Atenas del s. $\mathrm{V}$ aC: la de definir lo más estrictamente posible esa institución matrimonial de la que depende el control de la descendencia legítima $y_{2}$ en última instancia, la existencia de auténticos ciudadanos nacidos de padre y madre atenięnse ${ }^{61}$.

\section{Cisandra Erinia}

En los dos casos que nos ocupan el impasse al que conduce la situación de doble alianza legítima sc rcsuclve de la manera más radical: tanto Deyanira como Clitemestra asesinarán a sus respectivos maridos, en nombre de un primer matrimonio que se reivindica como el único posible. Pero también Casandra y Yole, en calidad de "causantes" de los asesinatos de los esposos, serán explícitamente identificadas como "vengadoras". Concretamente, serán asociadas a la Erinia, la más agresiva de las representaciones justicieras ideadas por los griegos ${ }^{62}$.

56. Ibidem, 310 .

57. Ibídem, 428: dámar, ibídem, 400, 545, 447, 486, 366: gyné. En este sentido G. Dumézil (Mariages Indo-Européens. Paris: Payot, 1079, p. 63) recuerda que "Heracles exige a su hijo la promesa de tomat a Yole no como amante, sino como legírima esposa, convirciéndolo en su honorable sustituton.

58. SOFOCLES. Traquiniats, 545.546 .

59. EURIPIDES, Electra, 10.33-34.

60. Ta misma que se detecta en el conocido caso de Medea y la princesa de Corinto: IRIARTE, A. "Las razones de Medeas". En MONLEON, J. (ed.). Tragedia griega y democracia. Mérida: Junta de Extremadura, 1989, p. 260.

61. El planteamiento trágico de la doble alianza legítima puede también relaçionarse con la poligamia como antigua práctica retomada por los tiranos de la época arcaica, un tipo de régimen muy utilizado por los trágicos como contrapunto para ensalzar los principios dernocrátiços. Véase la introducción de J.P. Vernant y P. Vidal-Naquet, op. cit., en la nota 1.

62. Casandra: EuRtPIDES, Troyanas. 457. Yole: SOFOCLES, Traquinias. 895. 
La homogeneidad de estatus sociales entre las primeras esposas y las recientes se prolonga en una misma acrirud beligerante con respecto al hombre, aunque dicha actitud tienc significados diferentes en cada caso, pues si las esposas que ya detentan el grado de madres toman venganza por el abandono de su lecho conyugal, las verdaderas "recién casadas" que son Casandra y Yole, lo hacen sobre todo en nombre de la destrucción de sus respectivas patrias.

Así lo dan a entender de forma especialmente clara las palabras que la propia Casandra dirige al mensajero que debe conducirla hasta el barco en el que Agamenón la llevará a Grecia: "Una de las tres Erinias en mí te vas a llevar. ¡Adiós madre, no me llores! Querida patria y hermanos que yacéis bajo tierra y tú, padre que nos engendró, no habréis de esperarme mucho. Llegaré al más allá triunfal (nikephóros) tras haber arruinado la casa de los Atridas que nos han destrozado" 63 .

Situadas en un punto intermedio entre la pureza virginal y la maternidad, ni Casandra ni Yole terminan de dar el paso hacia la feminidad plena. Pero es precisamente esta indeterminación la que les permitc seguir representando a sus propias familias, pucs cuando la mujer griega se casa y procrea para la lamilia de su marido deja de representar a su propio hogar ${ }^{6 / 4}$.

La encarnación más extrema de estc enfrentamiento entre matrimonio y familia es Antígona, quien lo asume hasta sus últimas consecuencias y de forma tan consciente como permite deducir el razonatniento que sigue: «Si un esposo se muere, otro podria tencr, y un hijo de otro hombre si hubiera perdido uno, pero cuando el padre y la madre están ocultos en el Hades no podría jamás nacer un hermano. $Y$ así, según estc principio, te he discinguido yo entre todos con mis honras, que parecieron a Creonte una falta y un terrible atrevimiento, oh hermano" 65 .

Ahora bien, el problema no se plantea en los mismos términos para Antígona que para Yole y Casandra. El drana de la primera consiste más bien en que debe elegir cntre su patria y su propia familia, dado que no puede someterse a las leyes de la ciudad sin despreciar las obligaciones que tiene para con los suyos; mientras que Casandra, y también Yole, aparecen como representantes de sus hogares sobre todo en el marco de un matrimonio en el que no se integran plenamente ya que, por su función de Erinias con respecto a Agamenón y Heracles, vengan a la vez a sus patrias y a sus familias.

En este sentido es curioso considerar otra vertiente de la leyenda de Casandra, que subraya su función de vengadora haciéndola aparecer como la responsable del gran naufragio que los griegos sufritán al volver de Troya a sus hogares. I a razón es que Atenea decidió vengar de esta manera el que los griegos no castigaran a Ayante por haber violado a Casandra en su templo ${ }^{66}$. Según

63. EuRfPIDES. Troyanas. 457-461. C. ibidem, 359-360. Ver EsQUILo, Agamenón, 1286 para la misma equivalencia entre la destrucción de su patria y la de la casa de los Atridas.

64. Como señala Vernant, J.P. Mythe et Pensée. Cit., en la nota 52, t. I, p. 148.

65. SOFOCLES, Antigona, $909-913$.

66. EURIPIDES, Troyanas, 71-94. Cf. Licofrón, Alejandra, 365-386. 
Licofrón ${ }^{67}$, este crimen del héroe de Locres se habría expiado, además, con la instauración de la costumbre de enviar diez doncellas locrias al templo de Atenea en Troya durante mil años ${ }^{68}$.

La virginidad ofendida de Casandra se convierte pues, por diferentes vías, en causa de castigo para los griegos que destruyeron su patria. Pero, como veremos a continuación, su muerte es el acto que mejor da cuenta de su carácter de Erinia vengadora, reforzando al mismo tiempo los lazos familiares que nunca rompió al no integrarse plenamente en una relación matrimonial.

\section{La muerte de Casandra}

Cuando, en el Agamenón, la hija de Príamo prevé que va a morir ho anuncia a sus interlocutores relacionando la desaparición de Troya con su propia desaparición: así como su patria ha perccido, ella va a caer a tierra ${ }^{69}$. Para Casandra morir es someterse al mismo destino que la ciudad de su padte, lo que en cierta forma acentúa su condición de vícrima pasiva. De hecho ante la noticia de que va a morir en cuanto entre en el palacio, el coro le pregunta: "Si de verdad conoces tu propia muerte, ecómo, igual que una ternera impulsada por los dioses (theelátou), marchas al altar con tal valentía ${ }^{70}$.

En estos versos los términos ternera — víctima sacrificial por excelencia-y altar remiten al tema del sacrificio ${ }^{7 t}$, y un poco más adelante la muette de Agamenón será igualmente presentada como un sacrificio por Clitemestra ${ }^{72}$. Pero, a diferencia de Agamenón, Casandra queda identificada más claramente como víctima sacrificial mediante el término theélatos, que expresa ese asentimiento que todo animal destinado al sacrificio debe manifestar para que su muerte pueda considerarse accptada por los dioses ${ }^{73}$. Esta aceptación explícita del destino que le ha sido reservado hace de Casandra una víctina del todo conforme a la norma ritual, incluyéndola en la serie de relatos míticos que narran el sacrificio de vírgenes ${ }^{7 / 4}$.

\section{Licofró, Alejandra. 1141-1173.}

68. De la historicidad de esta práctica da testimonio la inscripción llamada «de las doncellas Loctias». Sobte este docunnento ver el extudio publicado por P. Vidal-Naques, en 1975, bajo el título "Les esclaves immortelles d'Athéna\%, e incluido más tarde cn Le chasseur noir. Paris, 1981, p. 249-266.

69. ESQUILO. Agamenón, 1171-1172. Cf. ibid., 1160.

70. ESQUILO. Agamenón, 1296-1297.

71. CasaBONA, J. Recherches sur le vocabulaire des sacrifices en grec. Aix-en Provence, 1966, p. 160.

72. ESQuilo. Agamenón, 1433.

73. Roussit., P. "I. thème du sacrifice volontaire dans la tragédie d'Euripiden. Reuue Belge de Philologie et I I'stoire (1922), p. 225. Crol\$ET, M. "Le tôle d'Admère dans l'Alkeste d'Euripide". R.E.G., 360 (1912), p. 1-11.

74. No obstante la identificación como víctimas sacrificiales no sólo afecta a las doncellas. El trabajo de H. king ("Sacrificial Blood: The Role of amnion in Ancient Crynecolngy". F.n SkINNFR, M. (cd.). Rescuing Creusa, Helios, 1987, p. 117-126) permite observat cómo, en el corpus Hipocrático, la sangre mestrual y la del parro son asociadas a la que brota en el sacrificio sangriento, mientras que la sangre de los guerreros jamás es identificada como tal, lo que revela la concepción más amplia de la mujer como victima sacrificial. 
Entre ellos es de destacar el tratamiento trágico del sacrificio de Políxena por su estrecha relación con el caso de Casandra: al igual que ésta fue ofrecida a Agamenón como "don" ${ }^{75}$ con el que el ejército muestra su agradecimiento al general griego, Políxena es considerada como el "presente " ${ }^{76}$ que los griegos ofrecen a Aquiles una vez muerto, es decir, el sacrificio de Políxena en honor a este héroe equivale a unirla a él.

El destino de estas dos hermanas será considerado idéntico por su propia madre, quién denuncia que sus hijas le han sido usurpadas - como Perséfone fue usurpada a Deméter - para que protagonicen una unión en el Hades, una boda-muerte. Identificando a Casandra y a Políxena al mismo tiempo como jóvenes casaderas y como niñas, la esposa de Príamo se lamenta en los siguientes términos: "Si crié a mis hijas para entregarlas a esposos de alto rango, otros, beneficiándose de ello, las arrancaron de mis brazos" 77 .

En la Hécuba, la propia Políxena se identificará con esta imagen del niño brutalmente separado de la madre para explicar la situación que afronta al enterarse de que va a ser inmolada en la tumba de Aquiles: "A mí, retoño tuyo, cual a ternera alimentada en los montes, desgraciada yo y desgraciada tú, me contemplarás arrancada de tus manos, degollada y conducida a Hades, a las tinieblas subterráneas, donde, junto a los muertos, desdichada me hallarć ${ }^{78}$.

Pero la joven princesa también expresa su deseo de morir afirmando que es lo que mejor puede pasarle en un discurso prolongado que termina de la siguiente manera: «Madre, no nos pongas ningún obstáculo, ni de palabra ni de obra. Aconséjame morir antes de caer en destino vergonzoso impropio de mi dignidad. Pues quien no suele probar las desgracias, toléralas, pero le duele poner su cuello bajo el yugo. Más dichosa sería yo muriendo que viviendo, pues vivir sin dignidad gran oprobio es ${ }^{79}$.

No pudiendo ya ser quien es, Políxena prefiere dejar de existir y expresa su decisión con tanta firmeza que sus palabtas son reconocidas como lógos, es decir, identificadas con el "discurso" que sólo los hombres expresan públicamente. De hecho, la admiración que el monólogo de Políxena produce entre los griegos que asisten a su sacrificio conficre a éste ese carácter "heroico" (tlémon) ${ }^{80}$ del que normalmente sólo gozan los guerreros muertos en el campo de batalla ${ }^{81}$.

75. Fsquilo. Agamenon. 950-955.

76. Eurfipldes. Troyanas. 623: Polixena es concretamente un géras, un presente ofrecido como signo honorifico. Cf. EURIPIDES. Hécuba. 124-129, para otra forma de asociación entre el sacrificio de Políxena y la entrega de Casandra a Agamenón; así como Troyanas, 40-44.

77. EURfPIDEs. Troyanats, 484-6. Cf. Ibid., 513.

78. Íden. Hécuba, 205-10

79. Ibídcm, 372. Cf. ibidem, 214-15. Una concepción de la muerte que Eurípides ilustra de forma más precisa en el diálogn que Hécuba y Andrómaca mantienen en torno al destino de Políxena: EuRfPIDES. Troyanas, 630-631.

80. EURIPIDES. Hécuba, 562.

81. Del carácter heroico que revisten los sacrificios de vírgenes ha dado cucnta LoRAUX, Nicole. Façons tragiques de tuer une femme. París: Hachette, 1985, p. 61 ss. y, especialmente, p. 81-82 (trad. esp., Madrid: Visor, 1989). 
Pero la terminología que da cuenta de la gloria y el renombre del soldado patriótico también es apropiada para describir la actitud de nuestra profetisa. En efecto, ante su renuncia a huir del lugar en el que sabe que le espera la muerte el coro del Agamenón le atribuye dos prerrogativas exclusivas del hoplita $^{82}$ : la de tener un "alma valiente" (eutólmou phrenós) y la de morir "gloriosamente" (eukleôs). Por otra parte, la significación heroica de la muerte de Casandra queda también acentuada por el hecho de que su asesinato se realiza con una espada ${ }^{83}$, es decir, con el artna asociada a la muerte del guerrero.

La princesa troyana y Agamenón son asesinados por una mujer en las mismas condiciones. Sin embargo, dicho acto adquiere un significado diferente en cada caso. Para Agamenón se trata de una muette indigna, dado que es un guerrero que en vez de morir en el campo de batalla ha caído en las redes ${ }^{84}$ que su propia mujer le ha tendido ${ }^{85}$. Mientras que, como acabamos de ver, para Casandra se trata de un acto valeroso tanto por su forma de afrontarlo como por su carácter implícito de contraataque al enemigo ${ }^{86}$. Un deralle en el que reconoceremos que los trágicos tienen siempre presente la división sexual, aunque a veces lo hagan, precisamente, para intercambiar los valores correspondienres a cada uno de los sexos.

En lo que a las Troyanas se refiere, este aspecto glorioso de la muerte de Casandra va unido explícitamente al rol de Erinia que ésta asume para el desrructor de su parria. Aśl lo afirma la propia profetisa en un monólogo que reproduce con fidelidad ciertos elementos del elogio fúnebre y que termina como sigue: "...no es corona desdeñable una muerte gloriosa (kalôs olésthat) por la ciudad, mientras que hay deshonor en lo contrario. Así pues no debes llorar, madre, por mi patria y mi boda. Para los que tú y yo más odiamos mi matrimonio será la ruina " ${ }^{8}$.

Considerando su unión-muerre con el general del ejército griego como un último y definitivo enfrentamiento con el enemigo, Casandra reivindica para sí misma un estatus similar al de sus valientes hermanos muertos por la patria. El mismo que, como hemos visto, le había atribuido el coro del Agamenón.

Este halo heroico con el que los trágicos envuelven a Casandra la desacredita como simple "mujer fatal", pero tampoco llega a convertirla en un personaje decididamente viril. Como hemos ido viendo, el hecho de "ser conducida ${ }^{88}$, ya sea al matrimonio, al sacrificio-muerte e incluso a la violación, define regularmente su trato con el mundo masculino, erigiéndola en paradigma de pasivi-

82. EsQuilo. Agamenón, 1302 y 1304.

83. 83 Ibídem, 1149. Cf. ibídem, 1528 y Esquilo. Coéfarts, 1011. En las Troyanas (361) el arma reservada a Casandra es el hacha.

84. FSQUILO. Agamenón, 1382-1383. CF. LiCofrón. Alejandra, 1099-1102.

85. Ídetn. Cuéfuras, 479-80.

86. İdem. Agamenón, 1279.

87. Euripides. Troyanats, 401-405. Cf. ibídem, 457-461 para el carácter victorioso de la actividad de Casandra.

88. agomari. ESQUilo. Agamenón, 1264 y 1276. Cf. EuRfpiDes. Troyanas, 355 y 70 para la imagen de Casandra "enviada" hacia el matrimonio por su madre o «arrastrada" por Ayante. 
dad, en ideal de feminidad. Aun considerando que dicha pasividad es el «arma de mujer" con el que ella actúa en el universo de la guerra, no puede afirmarse que la complejidad del carácter de Casandra se resuelve cn una simple inversión de los roles sexuales.

En la tragedia se dan hombres afeminados como Egisto ${ }^{89}$, el amantc de Clitemestra que vive como un "extranjero" en el palacio de Agamenón mientras éste se encuentra en la guetra.

La tragedia también presenta en escena mujeres hombrunas como Clitemestra, a la que se designa como la mujer-hombre y cuya virilidad va en detrimento de la de Agamenón, al que ha deparado una muerte tan poco valerosa.

Pero este caso de completa inversión no es el de la figura que hemos tratado. A mi modo de ver, con Casandra se señala más bien la inevitable trascendencia del comportamiento femenino en el ámbito masculino de la acción. Trascendencia que no sicmpre tiene porqué presentarse en forma de usurpación de los valores masculinos.

Cuando se trata de dar cuenta de la gama de matices que conecta el polo femenino con el tnasculino, los trágicos hilan fino, por mucho que permanezcan encorsctados en esa lengua griega de la que podría decirse, al igual que de la nuestra, que escasea en terminología precisa para dar cucnta del heroismo en femenino.

Cuando se trata de reflexionat desde el punto de vista del género, los trágicos no se limitan a reproducir la diferencia entre hombres y mujeres tomando partido por una de las dos facciones, sino que atienden muy especialmente a los grados de reciprocidad que pueden darse entre género masculino y femenino. Lo cual implica la convicción de que la diferencia entre los scxos depende de convenciones sociales; convenciones que, al menos en el escenario trágico, pueden tambalear al verse confrontadas con otros sistemas a través de bárbaras legendarias como Casandra o sus hermanas trágicas.

\section{Nota biográfica}

Ana Iriarte es profesora titular de Historia Antigua en la Universidad del País Vasco. Ls autora de diversos artículos de carácter científico y ha publicado el libro Las redes del enigma. Voces femeninas en el pensamiento griego (Madrid, Taurus 1990). 